\title{
Longitudinal trends in thyroid function in relation to iodine intake: ongoing changes of thyroid function despite adequate current iodine status
}

\author{
Annenienke C van de Ven ${ }^{1}$, Romana T Netea-Maier ${ }^{1}$, H Alec Ross ${ }^{2}$, \\ Teun A E van Herwaarden², Suzanne Holewijn³, Jacqueline de Graaf ${ }^{3}$, \\ Bart L A Kiemeney ${ }^{4,5}$, Doorlène van Tienoven², Jack F M Wetzels ${ }^{6}$, Johannes W Smit ${ }^{1}$, \\ Fred C G J Sweep², Ad R M M Hermus ${ }^{1}$ and Martin den Heijer 1,4,7 \\ ${ }^{1}$ Division of Endocrinology, Department of Medicine, ${ }^{2}$ Department of Laboratory Medicine, ${ }^{3}$ Division ofVascular \\ Medicine, Department of Medicine, ${ }^{4}$ Department for Health Evidence, ${ }^{5}$ Department of Urology, ${ }^{6}$ Department of \\ Nephrology, Radboud University Nijmegen Medical Centre, PO Box 9101, 6500 HB Nijmegen, The Netherlands and \\ ${ }^{7}$ Section of Endocrinology, Department of Internal Medicine, VU University Medical Center, Amsterdam, \\ The Netherlands
}

\author{
Correspondence \\ should be addressed to \\ A C van de Ven \\ Email \\ A.vandeVen@endo.umcn.nl
}

\begin{abstract}
Objective: Several cross-sectional studies on populations with iodine deficiency showed that TSH-levels are negatively associated with age, while in populations with high iodine intake TSH is positively associated with age. The question is whether such an age-thyroid function relation is an ongoing process apparent also in longitudinal studies and whether it reflects an actual iodine deficiency or an iodine insufficiency in the past.

Methods: In an area with a borderline iodine status in the past, we studied 980 participants of the Nijmegen Biomedical Study. We measured serum $\mathrm{TSH}$, free thyroxine $\left(\mathrm{FT}_{4}\right)$, total triiodothyronine $\left(\mathrm{T}_{3}\right)$, peroxidase antibodies, and the urine iodine and creatinine concentration 4 years after our initial survey of thyroid function, in which we reported a negative association between TSH and age.

Results: Within 4 years, TSH decreased by 5.4\% (95\% Cl 2.5-8.3\%) and $\mathrm{FT}_{4}$ increased by 3.7\% (95\% Cl 2.9-4.6\%). Median urinary iodine concentration was $130 \mu \mathrm{g} / \mathrm{l}$. Estimated 24-h iodine excretion was not associated with TSH, $\mathrm{T}_{3}, \mathrm{change}$ of TSH, or $\mathrm{FT}_{4}$ over time or with the presence of antibodies against thyroid peroxidase. Only $\mathrm{FT}_{4}$ appeared to be somewhat higher at lower urine iodine levels: a $1.01 \%(95 \% \mathrm{Cl} 0.17-1.84 \%)$ higher $\mathrm{FT}_{4}$ for each lower iodine quintile.

Conclusions: In this longitudinal study, we found an ongoing decrease in TSH and increase in $\mathrm{FT}_{4}$ in a previously iodine insufficient population, despite the adequate iodine status at present. This suggests that low iodine intake at young age leads to thyroid autonomy (and a tendency to hyperthyroidism) that persists despite normal iodine intake later in life.

\section{Introduction}

Iodine is an essential micronutrient and an important component of thyroid hormones. Iodine deficiency can cause thyroid dysfunction, goiter, and cretinism (1). Monitoring the iodine status and maintaining an optimal iodine intake are very important to prevent brain damage in newborns and thyroid function disorders at all ages. Iodine deficiency remains a global public health problem (2). To assess the iodine status of a population, the median 
iodine concentration of series of single urine samples is the most widely used measurement $(1,3)$. In large population studies, there is a leveling out of the dayto-day variation, and the median value of the urinary iodine concentration in samples can be used to assess whether a population is iodine sufficient (4). According to the World Health Organization (WHO) criteria, a population has an optimal iodine intake if its median urine iodine concentration is between 100 and $199 \mu \mathrm{g} / \mathrm{l}$ and no more than $20 \%$ of the population has an urinary iodine concentration of $50 \mu \mathrm{g} / \mathrm{l}$ or less $(1,3)$.

In the past, mild iodine deficiency was present in the eastern and southern part of The Netherlands $(5,6,7)$. Iodine supplements were instituted as of 1935 . Since then, several additional measures, like the compulsory use of iodized salt in bakeries, instituted in 1963, were taken to achieve a daily intake of iodine within the optimal range as recommended by the WHO (3). Currently, the iodine status of The Netherlands is considered to be adequate, based on studies regarding the iodine intake and urinary excretion in several regions in The Netherlands $(2,8,9,10,11,12)$. Owing to decrease in salt consumption and reduced bread consumption, regular monitoring of the iodine status in the population is necessary to verify the maintenance of adequate iodine status (13).

Previous cross-sectional population studies have shown that in populations with a history of mild or moderate iodine deficiency, the average serum level of thyroid-stimulating hormone (TSH) is negatively associated with age, and free thyroxine $\left(\mathrm{FT}_{4}\right)$ is positively associated with age, which is probably due to the gradual development of autonomous function of the thyroid gland $(14,15,16)$. By contrast, in populations with high iodine intake, TSH is positively associated with age (17). In subjects of the Nijmegen Biomedical Study (NBS), a large population-based survey performed in Nijmegen, a municipality in the eastern part of The Netherlands, TSH is negatively associated with age and $\mathrm{FT}_{4}$ is positively associated with age (14). These associations were found in cross-sectional surveys. The question is whether such an age-thyroid function relation is apparent also in longitudinal analyses and, if so, whether it reflects an actual iodine deficiency.

\section{Subjects and methods}

\section{Subjects}

The subjects of this study are a subset of the participants of the NBS, a large population-based survey performed in
Nijmegen, a town in the eastern part of The Netherlands. Details of this study have been described previously (14). Approval to conduct the study was obtained from the Institutional Review Board of the Radboud University Nijmegen Medical Centre (RUNMC). A total of 2253 respondents, aged $50-72$ years, were invited to participate in a study of non-invasive measurements of atherosclerosis (NBS-NIMA), of whom 1517 gave their informed consent. In 1052 participants of this subgroup, the iodine concentration was measured in fasting morning urine samples in 2006. Serum TSH and $\mathrm{FT}_{4}$ were measured twice with an interval of 4 years (2002 and 2006). The mean interval between the measurements was 4.1 years (range 2.8-5.4 years). Triiodothyronine $\left(\mathrm{T}_{3}\right)$ and antibodies against thyroid peroxidase (TPOAb) were measured in 2006. We excluded subjects with previously known thyroid disease, a medical history of thyroid surgery or iodine treatment, the use of thyromimetic and/or thyrostatic drugs, and the use of medication interfering with thyroid function or iodine status such as amiodarone, kelp, oral corticosteroids, dopamine agonists, and lithium. A total of 72 participants were excluded, so in total 980 participants were included in the current analysis.

\section{Laboratory methods}

Serum TSH and $\mathrm{T}_{3}$ were measured by an immunoluminometric assay on a random-access analyzer (Architect; Abbott Laboratories). The reference interval for serum TSH used in our laboratory is $0.4-4.0 \mathrm{mIU} / 1$. Serum $\mathrm{FT}_{4}$ was measured with a luminescence enzyme immunoassay on a random-access assay system (Vitros ECI; Ortho Clinical Diagnostics, Rochester, NY, USA). Our laboratory reference interval is $8.0-22.0 \mathrm{pmol} / 1$. TPOAbs were measured with a fluorescence immunoenzymometric assay for the quantitative measurement of the IgG class of anti-TPOAbs (AxSYM, Abbott Laboratories). The reference interval was defined as $<12 \mathrm{kIU} / 1$ (data provided by manufacturer). More details about these measurements are described elsewhere (14). In order to control a possible drift in assays between the two study periods, we repeated $\mathrm{TSH}$ and $\mathrm{FT}_{4}$ measurements of pooled plasma with TSH and $\mathrm{FT}_{4}$ in the lower, middle, and higher range. For TSH, the control samples showed a drift of $-2.2,-6.0$, and $-9.6 \%$ for the lower, middle, and higher range respectively. For $\mathrm{FT}_{4}$, the control samples showed a drift of $-9.7,-5.7$, and $-1.8 \%$ for the lower, middle, and higher range respectively. We suspected that a bias was introduced during analysis of the control samples, perhaps by sample instability in the 
freezer or some other unknown factor. Therefore, we choose to use the original results of the assays.

To assess the iodine status of our population, we calculated the median urinary iodine concentration, obtained from single urinary samples, as recommended by the WHO $(1,3)$. For the individual subjects, we used the estimated 24-h iodine excretion, adjusted for age and gender, as an indicator for the iodine status. The estimated 24-h urinary iodine excretion was calculated as follows: iodine $(\mu \mathrm{g} / \mathrm{l}) /$ creatinine $(\mathrm{g} / \mathrm{l}) \times$ expected 24 -h creatinine (g/day) $(18,19,20)$. A large Belgian population study provides data on the expected creatinine excretion per individual, taking age and sex into account (21). The urine iodine concentration was measured with the Ammonium Persulfate Destruction Microplate (APDM) method, using a Peltier Thermal Cycler (PTC-200) for the heating and cooling process (22). The urinary creatinine concentration was measured by an enzymatic assay (Roche) on the Aeroset chemistry analyzer (Abbott Laboratories).

\section{Statistical analysis}

Because of a skewed distribution of the urinary iodine concentration, we used quintiles of the estimated 24-h urinary iodine excretion for stratification. We displayed geometric means of $\mathrm{FT}_{4}$ and $\mathrm{TSH}$ with its 95\% CIs. We expressed change over time of TSH and $\mathrm{FT}_{4}$ as a percentage of change. We performed logarithmic transformation of $\mathrm{FT}_{4}$ and TSH for regression analysis. Linear regression analysis was performed in order to investigate the relationship between thyroid function and iodine excretion. Each model included the estimated 24-h urine iodine excretion as the independent variable and a thyroid function parameter (either $\mathrm{FT}_{4}, \mathrm{~T}_{3}$, TSH, or change of TSH or $\mathrm{FT}_{4}$ over time) as the dependent variable. To control for possible confounding, we added age, gender, BMI, and current smoking status to the models. We analysed the data with STATA, version 11.0 (StataCorp., College Station, TX, USA).

\section{Results}

The characteristics of the population are shown in Table 1 . The median urinary iodine concentration was $130 \mu \mathrm{g} / \mathrm{l}$. The median urinary iodine concentration was higher in men in comparison with women, $156 \mathrm{vs} 104 \mu \mathrm{g} / 1$ respectively. The urinary iodine concentration was $<50 \mu \mathrm{g} / \mathrm{l}$ in $15 \%$ of the participants. The urinary iodine concentration was $<50 \mu \mathrm{g} / \mathrm{l}$ in $9 \%$ of the men and in $20 \%$ of the women. Owing to a higher urinary creatinine concentration, men had a lower urinary iodine:creatinine ratio (I:C ratio) in comparison with women (135 vs $171 \mu \mathrm{g} / \mathrm{g}$ respectively). However, the median estimated 24-h urinary iodine excretion, taking age and gender into account, was higher in men in comparison with women (208 vs $186 \mu \mathrm{g} /$ day respectively).

During the follow-up period of 4 years, the average TSH decreased with $5.4 \%$ (95\% CI $2.5-8.3 \%, P$ value $<0.001)$ and $\mathrm{FT}_{4}$ increased with $3.7 \%$ (95\% CI 2.9-4.6\%, $P$ value $<0.001)$ (Table 1$)$.

A lower quintile of estimated 24-h iodine excretion was associated with a $1.01 \%$ higher $\mathrm{FT}_{4}$ (95\% CI $0.17-$ $1.84 \%, P$ for trend along quintiles 0.02 , adjusted for age, gender, BMI, and current smoking status). There was no significant association between the TSH level and the estimated 24-h iodine excretion after adjustment for age, gender, BMI, and current smoking status: a lower quintile of urinary iodine excretion resulted in a $0.17 \%$ higher serum TSH (95\% CI -3.0 to $3.2 \%, P$ for trend along quintiles 0.92). There was no association between $\mathrm{T}_{3}$ and the estimated 24-h iodine excretion.

There was no association between iodine excretion and the percentage of decrease in TSH or increase in $\mathrm{FT}_{4}$ : a higher quintile of the estimated 24-h iodine excretion resulted in a $1.4 \%$ stronger decrease in TSH over time (95\% CI -1.0 to $3.6 \%, P$ for trend along quintiles 0.25 after adjustment for age, gender, BMI, and current smoking status) and a lower quintile of the estimated 24 -h iodine excretion resulted in a $0.4 \%$ stronger increase of $\mathrm{FT}_{4}$ over time $(95 \% \mathrm{CI}-0.3$ to $1.0 \%, P$ for trend along quintiles 0.26 after adjustment for age, gender, BMI, and current smoking status).

There was no relationship between the presence of TPOAb and estimated 24-h urinary iodine excretion (data not shown). After exclusion of subjects with TPOAb, the analyses of $\mathrm{TSH}_{1} \mathrm{FT}_{4}$, and $\mathrm{T}_{3}$ gave similar results (data not shown). Analyses with $\mathrm{TSH}_{\text {or }} \mathrm{FT}_{4}$ and iodine as (log transformed) continuous variables gave similar results (data not shown).

\section{Discussion}

Despite the fact that our population has an optimal iodine intake at this moment, we found an ongoing decrease in TSH and increase in $\mathrm{FT}_{4}$ over time. The decrease in $\mathrm{TSH}$ and the increase in $\mathrm{FT}_{4}$ in the 4-year follow-up period were even larger than we expected, based on the cross-sectional data in 2002. Iodine excretion was in the recommended range and was not associated with a change in $\mathrm{TSH}_{\text {or }} \mathrm{FT}_{4}$. One might speculate that the decrease in TSH and increase in $\mathrm{FT}_{4}$ with age in our population is caused by mild iodine 
Table 1 Population characteristics.

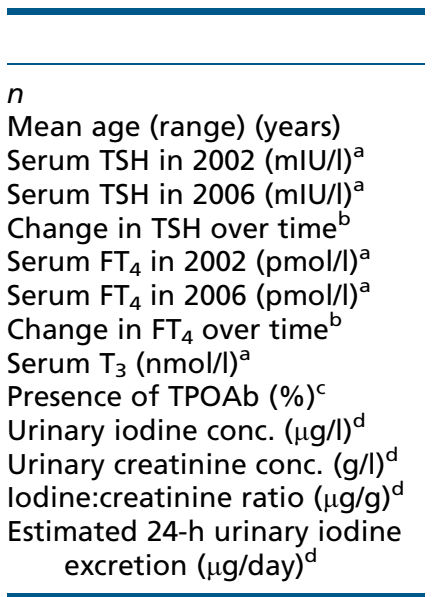

Total
980
$61(50$ to 72$)$
$1.35(1.30$ to 1.41$)$
$1.29(1.24$ to 1.34$)$
$-5.4 \%(-8.3$ to $-2.5 \%)$
$13.0(12.9$ to 13.1$)$
$13.5(13.3$ to 13.6$)$
$3.7 \%(2.9$ to $4.6 \%)$
$1.61(1.59$ to 1.62$)$
$115(11.9 \%)$
$130(70$ to 211$)$
$0.89(0.4$ to 1.5$)$
$154(109$ to 212$)$
$199(145$ to 274$)$

\begin{tabular}{c}
\hline Men \\
\hline 492 \\
$62(50$ to 72$)$ \\
$1.35(1.28$ to 1.42$)$ \\
$1.30(1.24$ to 1.36$)$ \\
$-5.5 \%(-8.6$ to $-2.4 \%)$ \\
$13.0(12.8$ to 13.2$)$ \\
$13.4(13.2$ to 13.6$)$ \\
$2.9 \%(1.7$ to $4.2 \%)$ \\
$1.61(1.59$ to 1.63$)$ \\
$27(5.6 \%)$ \\
$156(91$ to 238$)$ \\
$1.2(0.7$ to 1.8$)$ \\
$135(101$ to 186$)$ \\
$208(151$ to 287$)$
\end{tabular}

\begin{tabular}{c} 
Women \\
\hline 488 \\
$61(50$ to 71$)$ \\
$1.35(1.27$ to 1.43$)$ \\
$1.28(1.20$ to 1.36$)$ \\
$-5.3 \%(-10.0$ to $0.3 \%)$ \\
$12.9(12.8$ to 13.1$)$ \\
$13.5(13.3$ to 13.8$)$ \\
$4.5 \%(3.3$ to $5.8 \%)$ \\
$1.60(1.58$ to 1.62$)$ \\
$88(18.2 \%)$ \\
$104(55$ to 176$)$ \\
$0.6(0.3$ to 1.0$)$ \\
$171(120$ to 241$)$ \\
$186(134$ to 262$)$ \\
\end{tabular}

$\mathrm{TSH}$, thyroid-stimulating hormone; $\mathrm{FT}_{4}$, free thyroxine; $\mathrm{TPOAb}$, antibodies against thyroid peroxidase; Conc., concentration. aGeometric means $(95 \% \mathrm{Cl})$.

${ }^{\mathrm{b}}$ Percentage change of TSH and $\mathrm{FT}_{4}$ from 2002 until 2006, geometric means $(95 \% \mathrm{Cl})$.

'TPOAb missing in 14 subjects.

${ }^{\mathrm{d}}$ Median (interquartile range).

deficiency in the past and not by iodine deficiency in the present. Iodine deficiency in the past may have led to autonomous thyroid function, which at present causes an ongoing increase in $\mathrm{FT}_{4}$ and decrease in TSH over time.

The mechanism by which mild iodine insufficiency leads to thyroid autonomy is only partially understood. In case of mild iodine deficiency, low iodine intake might lead to a reduced $\mathrm{T}_{4}$ and $\mathrm{T}_{3}$ production. In order to prevent this, several TSH-independent autoregulatory mechanisms are triggered, such as an increase in vascularity, an increase in iodine uptake, and increased $\mathrm{T}_{3}$ production and secretion, at the expense of $\mathrm{T}_{4}$ (23). If these mechanisms fail, TSH levels will rise as a response to a lower thyroid hormone production. TSH stimulates follicular cell replication and due to the higher replication rate, the chance of activating mutations in the TSH-receptor gene leading to TSH-independent growth and function is increased (24). This and other mechanisms lead to autonomous function of the thyroid and, especially when iodine intake is supplemented, to hyperthyroidism.

We found that a lower estimated 24-h iodine excretion was associated with a somewhat higher serum $\mathrm{FT}_{4}$. However, we found no relationship between TSH and the estimated 24-h urinary iodine excretion. Previous studies reported conflicting results on the relationship between urinary iodine excretion and thyroid function. Haddow et al. (25) found no relationship between urine iodine concentration and thyroid function and only a weak positive association between the urinary I:C ratio and TSH. Their study was performed in an iodine sufficient population, where TSH increases with age (17). Hwang et al. (26) found that the urinary I:C ratio had a negative correlation with $\mathrm{FT}_{4}$ and showed a positive trend with TSH in a Korean population, with a high iodine intake. In this Korean study, creatinine adjustment of urine iodine measurements was done without taking gender and age into account.

We used the estimated 24 -h iodine excretion, adjusted for age and gender, as an indicator for the iodine status of individuals. Assessing the iodine status of individuals is difficult. The within-day and day-to-day variation in urinary iodine excretion are large (27). Therefore, repeated 24-h urine samples are considered to be the best measure (28). However, 24-h collections are not very practical to perform when large numbers of persons have to be investigated. To minimize the variation in urinary iodine concentration caused by a variable urinary volume, the I:C ratio has also been used to assess the iodine status. However, creatinine excretion varies with sex, age, cultural, and genetic background. That is the reason why adjustment for age and sex is recommended $(18,19,27,28)$. This can be done by estimating the 24 -h iodine excretion, using the expected 24-h creatinine. A large Belgian population study provides data on the expected creatinine excretion per individual, taking age and sex into account (21).

Our study has a few limitations. Our study is a subset of a large epidemiological study, the NBS-NIMA study. Because of the nature of the NBS-NIMA survey, urinary iodine measurements were only performed in subjects 
aged between 50 and 72 years old. Second, as already mentioned, assessing the iodine status of an individual is difficult due to variation in iodine intake and excretion. Owing to the variation in iodine excretion, the relationship between iodine excretion and thyroid function parameters might be underestimated as a result of regression dilution bias $(29,30,31)$. Third, the fact that sera from 2002 and 2006 were assayed several years apart introduced a potential bias. Although this potential bias by variation in assay is inescapable in every large population study using biochemical analyses at different moments, this problem is not always recognized and addressed. Finally, although previous population studies have shown an iodine insufficiency in the past in this part of The Netherlands, we have no historical data on iodine excretion of this cohort to support our hypothesis that the current changes in thyroid function are due to iodine insufficiency in the past $(5,6,7)$.

In conclusion, in this longitudinal study, we found an ongoing decrease in TSH and increase in $\mathrm{FT}_{4}$ in a previously iodine insufficient population, despite the adequate iodine status at present. This suggests that low iodine intake at young age leads to thyroid autonomy (and a tendency to hyperthyroidism) that persists despite normal iodine intake later in life.

\section{Declaration of interest}

The authors declare that there is no conflict of interest that could be perceived as prejudicing the impartiality of the research reported.

\section{Funding}

This research did not receive any specific grant from any funding agency in the public, commercial or not-for-profit sector.

\section{References}

1 World Health Organization, United Nations Children's Fund \& International Council for Control of Iodine Deficiency Disorders. Indicators for assessing iodine deficiency disorders and their control through salt iodization. WHO/NUT/94-6. World Health Organization, Geneva, 1994.

2 de Benoist B, McLean E, Andersson M \& Rogers L. Iodine deficiency in 2007: global progress since 2003. Food and Nutrition Bulletin 200829 195-202.

3 World Health Organization, United Nations Children's Fund \& International Council for Control of Iodine Deficiency Disorders. Assessment of iodine deficiency disorders and monitoring their elimination. Geneva: WHO/NHD/01.1, 2001.

4 Andersen S, Karmisholt J, Pedersen KM \& Laurberg P. Reliability of studies of iodine intake and recommendations for number of samples in groups and in individuals. British Journal of Nutrition 200899 813-818. (doi:10.1017/S0007114507842292)
5 van Rees-Wortelboer MM, Schroder-van der Elst JP, Lycklama A \& van der Heide D. Iodine and goiter in The Netherlands. Nederlands Tijdschrift voor Geneeskunde $1987 \mathbf{1 3 1}$ 1821-1824.

6 Brug J, Lowik MR, Wedel M \& Odink J. Iodide excretion before and after revision of goiter prophylaxis (Dutch Nutrition Surveillance System). European Journal of Clinical Nutrition 199246 671-678.

7 Health Council of The Netherlands. Adviezen inzake jodiumvoorzieningen. Verslagen, Adviezen, Rapporten No.78, Staatsuitgeverij, The Hague, The Netherlands, 1981.

8 Brussaard JH, Hulshof KF, Kistemaker C \& Lowik MR. Adequacy of the iodine supply in The Netherlands. European Journal of Clinical Nutrition 199751 (Suppl 4) S11-S15.

9 Brussaard JH, Brants HA, Hulshof KF, Kistemaker C \& Lowik MR. Iodine intake and urinary excretion among adults in the Netherlands. European Journal of Clinical Nutrition 199751 (Suppl 3) S59-S62.

10 Wiersinga WM, Podoba J, Srbecky M, van Vessem M, van Beeren HC \& Platvoet-Ter Schiphorst MC. A survey of iodine intake and thyroid volume in Dutch schoolchildren: reference values in an iodinesufficient area and the effect of puberty. European Journal of Endocrinology 2001144 595-603. (doi:10.1530/eje.0.1440595)

11 Delange F, Benker G, Caron P, Eber O, Ott W, Peter F, Podoba J, Simescu M, Szybinsky Z, Vertongen F et al. Thyroid volume and urinary iodine in European schoolchildren: standardization of values for assessment of iodine deficiency. European Journal of Endocrinology 1997 136 180-187. (doi:10.1530/eje.0.1360180)

12 Health Council of The Netherlands. In Towards Maintaining an Optimal Iodine Intake. Publication no 2008/14. The Hague, The Netherlands, 2008.

13 Verkaik-Kloosterman J, van 't Veer P \& Ocke MC. Reduction of salt: will iodine intake remain adequate in The Netherlands? British Journal of Nutrition 2010104 1712-1718. (doi:10.1017/S0007114510002722)

14 Hoogendoorn EH, Hermus AR, de Vegt F Ross HA, Verbeek AL, Kiemeney LA, Swinkels DW, Sweep FC \& den Heijer M. Thyroid function and prevalence of anti-thyroperoxidase antibodies in a population with borderline sufficient iodine intake: influences of age and sex. Clinical Chemistry 200652 104-111. (doi:10.1373/clinchem. 2005.055194)

15 Laurberg P, Pedersen KM, Hreidarsson A, Sigfusson N, Iversen E \& Knudsen PR. Iodine intake and the pattern of thyroid disorders: a comparative epidemiological study of thyroid abnormalities in the elderly in Iceland and in Jutland, Denmark. Journal of Clinical Endocrinology and Metabolism 199883 765-769. (doi:10.1210/jc.83.3. 765)

16 Laurberg P, Cerqueira C, Ovesen L, Rasmussen LB, Perrild H, Andersen S, Pedersen IB \& Carlé A. Iodine intake as a determinant of thyroid disorders in populations. Best Practice \& Research. Clinical Endocrinology \& Metabolism 201024 13-27. (doi:10.1016/j.beem.2009. 08.013)

17 Hollowell JG, Staehling NW, Flanders WD, Hannon WH, Gunter EW, Spencer CA \& Braverman LE. Serum TSH, T(4), and thyroid antibodies in the United States population (1988 to 1994): National Health and Nutrition Examination Survey (NHANES III). Journal of Clinical Endocrinology and Metabolism 200287 489-499. (doi:10.1210/jc.87.2. 489)

18 Knudsen N, Christiansen E, Brandt-Christensen M, Nygaard B \& Perrild H. Age- and sex-adjusted iodine/creatinine ratio. A new standard in epidemiological surveys? Evaluation of three different estimates of iodine excretion based on casual urine samples and comparison to $24 \mathrm{~h}$ values. European Journal of Clinical Nutrition 200054 361-363. (doi:10.1038/sj.ejcn.1600935)

19 Rasmussen LB, Ovesen L, Bulow I, Jørgensen T, Knudsen N, Laurberg P $\&$ Perrild $\mathrm{H}$. Relations between various measures of iodine intake and thyroid volume, thyroid nodularity, and serum thyroglobulin. American Journal of Clinical Nutrition 200276 1069-1076.

20 Vejbjerg P, Knudsen N, Perrild H, Laurberg P, Andersen S, Rasmussen LB, Ovesen L \& Jørgensen T. Estimation of iodine intake 
from various urinary iodine measurements in population studies. Thyroid 200919 1281-1286. (doi:10.1089/thy.2009.0094)

21 Kesteloot $\mathrm{H} \&$ Joossens JV. On the determinants of the creatinine clearance: a population study. Journal of Human Hypertension $1996 \mathbf{1 0}$ 245-249.

22 Ohashi T, Yamaki M, Pandav CS, Karmarkar MG \& Irie M. Simple microplate method for determination of urinary iodine. Clinical Chemistry 200046 529-536.

23 Obregon MJ, Escobar del Rey F \& Morreale de Escobar G. The effects of iodine deficiency on thyroid hormone deiodination. Thyroid 200515 917-929. (doi:10.1089/thy.2005.15.917)

24 Tonacchera M, Agretti P, Chiovato L, Rosellini V, Ceccarini G, Perri A, Viacava P, Naccarato AG, Miccoli P, Pinchera A et al. Activating thyrotropin receptor mutations are present in nonadenomatous hyperfunctioning nodules of toxic or autonomous multinodular goiter. Journal of Clinical Endocrinology and Metabolism 200085 2270-2274. (doi:10.1210/jc.85.6.2270)

25 Haddow JE, McClain MR, Palomaki GE \& Hollowell JG. Urine iodine measurements, creatinine adjustment, and thyroid deficiency in an adult United States population. Journal of Clinical Endocrinology and Metabolism 200792 1019-1022. (doi:10.1210/jc.2006-2156)

26 Hwang S, Lee EY, Lee WK, Shin DY \& Lee EJ. Correlation between iodine intake and thyroid function in subjects with normal thyroid function.
Biological Trace Element Research 2011143 1393-1397. (doi:10.1007/ s12011-011-8997-x)

27 Andersen S, Pedersen KM, Pedersen IB \& Laurberg P. Variations in urinary iodine excretion and thyroid function. A 1-year study in healthy men. European Journal of Endocrinology 2001144 461-465. (doi:10.1530/eje.0.1440461)

28 Rasmussen LB, Ovesen L \& Christiansen E. Day-to-day and within-day variation in urinary iodine excretion. European Journal of Clinical Nutrition 199953 401-407. (doi:10.1038/sj.ejcn.1600762)

29 Clarke R, Shipley M, Lewington S, Youngman L, Collins R, Marmot M \& Peto R. Underestimation of risk associations due to regression dilution in long-term follow-up of prospective studies. American Journal of Epidemiology 1999150 341-353. (doi:10.1093/oxfordjournals.aje. a010013)

30 Hutcheon JA, Chiolero A \& Hanley JA. Random measurement error and regression dilution bias. BMJ $2010340 \mathrm{c} 2289$. (doi:10.1136/bmj. c2289)

31 Van de Ven AC, Netea-Maier RT, Medici M, Sweep FC, Ross HA, Hofman A, de Graaf J, Kiemeney LA, Hermus AR, Peeters RP et al. Underestimation of effect of thyroid function parameters on morbidity and mortality due to intra-individual variation. Journal of Clinical Endocrinology and Metabolism 201196 E2014-E2017. (doi:10.1210/jc. 2011-0680)

Received 18 July 2013

Revised version received 21 September 2013

Accepted 10 October 2013 